\title{
The investigation of boiling crisis of nanofluids
}

\author{
Andrey Minakov ${ }^{1,2, a}$, Maxim Pryazhnikov ${ }^{1}$, Vladimir Zhigarev ${ }^{1}$ and Valery Rudyak ${ }^{3}$ \\ ${ }^{1}$ Siberian Federal University \\ ${ }^{2}$ Institute of Thermophysics SB RAS \\ ${ }^{3}$ Novosibirsk State University of Civil Engineering
}

\begin{abstract}
Saturated boiling of nanofluids on a cylindrical heater with different diameters is experimentally studied. Studied nanofluids were prepared using distilled water and different metal oxides nanoparticles. The volume concentration of the nanoparticles was changed from 0.05 to $1 \%$. It has been measured that the critical heat flux for nanofluids was much higher than for water. A strong dependence of $\mathrm{CHF}$ on the material and size of the nanoparticles and duration of boiling and size of heater was shown.
\end{abstract}

\section{Introduction}

Studies of the last two decades have shown that nanofluids have unusual transfer properties. In particular, small adds of nanoparticles into carrying liquid can considerably increase its heat conductivity and viscosity [1-4]. This stimulated many thermophysical applications of nanofluids, particularly, aimed at intensification of heat exchange. It has been found that nanofluids have really enhanced coefficients of heat transfer (see, for example, $[5,6]$ and literature cited there in). The further intention to increase this coefficient stimulated the study of heat transfer of nanofluids during boiling. These works have been performed quite intensely during the last decade. Nevertheless, the obtained results are rather contradictory. For example, in [7] it is noted that adding of nanoparticles does not change heat transport considerably, with an even decrease in the heat transfer coefficient during boiling been seen in [8]. Conversely, in [9-11], this coefficient rose.

In this paper an experimental study of saturated boiling of nanofluids on cylindrical heaters micro sizes. The aim of this study was to study the effect of nanoparticles on critical heat flux (CHF) during boiling. And also study the effect of the size of the heater. As the heater used nichrome wire of various diameters. Heater diameter ranged from 100 microns to 300 microns.

\section{Experimental apparatus and procedure}

In this work, the effect of nanoparticles on critical density of heat flow during boiling was studied. Studies of thermophysical properties of nanofluids have shown that they generally depend not only on the volume concentration of particles, but also on their sizes [3, 12, 13]. Therefore, in this work, nanofluids with considerably different nanoparticle sizes were considered. In all cases, the carrying liquid was distilled water and diamond nanoparticles, iron oxide (III) and $\mathrm{SiO}_{2}$ nanoparticles with volume concentration from 0.05 to $1 \%$ were used. To prepare nanoparticles, a standard two stage process was used. After adding some quantity of the nanopowder to water, a vessel with the 
nanoliquid was put for half an hour in a UZDNA - ultrasonic disperser to decompose nanoparticle aggregates. All particle sizes given in the paper this is the sizes of conglomerates. Measurement of conglomerates distribution in the fluid in terms of their size was carried out by means of the CPS Disk Centrifuge DC24000. The particle size measurement carried out in the liquid. Therefore, the size of the conglomerates are taken into account automatically.

The scheme of the experimental setup scheme was described in [14-15]. The studied liquid was placed in a sealed glass flask $8 \mathrm{~cm}$ in diameter. The liquid volume in the flask was $300 \mathrm{~mL}$. A nichrome wire with diameter $d=100,200,300$ micron, length $L=34 \mathrm{~mm}$ fixed by copper cables was put as a heater in the vessel with the liquid. The flask with the studied liquid was sealed; therefore, the formed condensate dropped into the flask, thus sustaining saturation conditions in the working chamber. To control the liquid temperature in the flask, a chromel-copel thermocouple was used, which was connected to TMP200 temperature potentiometer. The end of the thermocouple was leveled with the nichrome heater at $2 \mathrm{~cm}$ distance from it. The reservoir with the studied liquid was placed into water bath in which, with the help of electric heater, a constant temperature was maintained, which was about $0.5^{\circ}$ lower than the boiling temperature.

\section{Results and discussion}

The critical heat load of the nanofluids changes considerably with an increase in the volume concentration of nanoparticles. The dependence of relative thermal load $q / q_{w}$ ( $q_{w}$ is the critical density of the heat flow for water) on the volume concentration of nanoparticles is shown in Fig. 1a. The here displayed values of heat flow critical density were obtained by averaging over five independent experiments. The critical density of heat for water was $q_{w}=1.32 \mathrm{MW} / \mathrm{m}^{2}$.
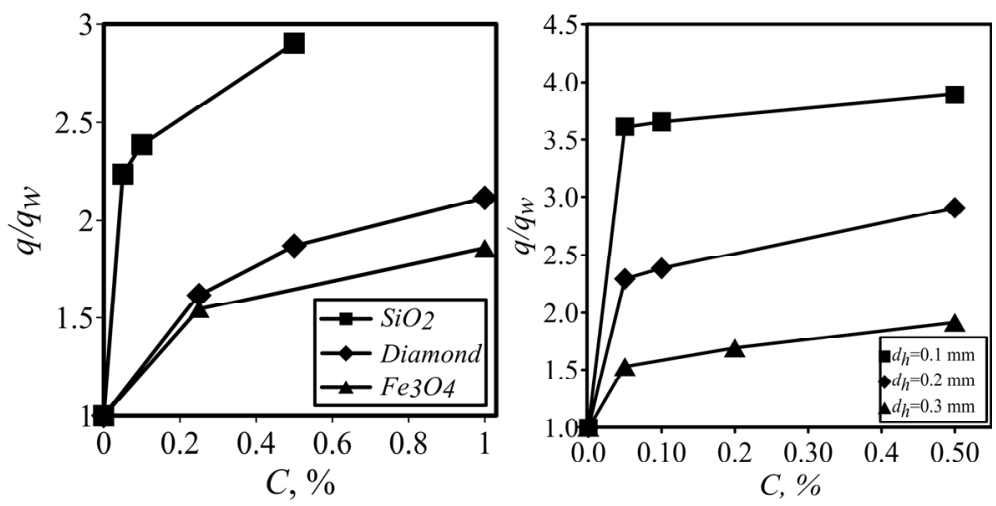

Figure 1. The dependence of critical heat flux density on the concentrations for different materials of nanoparticles (a), and for different diameter (b) of nichrome heater.

Analysis of heat flux density behavior during boiling of nanofluids shows that the use of nanoparticles brings about a considerable increase in the critical thermal load. Especially for nanoparticle $\mathrm{SiO}_{2}$. As early as at a volume particle concentration of $0.25 \%$, the critical density of the heat flux increases by more than $100 \%$ and continues to rise with further increase in the concentration of nanoparticles. Hence, use of nanofluids can significantly increase the value of the thermal load as compared to a conventional heat carrier and, consequently, this can increase the energy efficiency of setups in which the main process is boiling.

It was further investigated the influence of the diameter of the heater on the value of the critical heat flux at the boiling. These studies were conducted for $\mathrm{SiO}_{2}$ nanofluids, because it showed the best results in the previous experiments (see Fig.1b). For these studies, a series of experiments with different diameters of the heaters was performed. As a heater used nichrome wire diameter 100, 200, 300 microns. The results of these measurements are shown in Fig.1b. It is seen that with decreasing diameter of the heater ratio increases dramatically for all concentrations. 
Also we investigated the influence of the diameter of the nanoparticle on the value of the critical heat flux at the boiling. These studies were conducted for $\mathrm{SiO}_{2}$ nanofluids and heater diameter 200 microns. The particle diameters ranged from $25 \mathrm{~nm}$ to $100 \mathrm{~nm}$. The results of these measurements are shown in Figure 2. It is evident that with decreasing particle diameter ratio is reduced. We think that this is due to the deposition of particles on the wall heater. During deposition of particles on the surface of the formed roughened surface (see Fig.3). With increase of the particle diameter size of the heater surface roughness increases. It is known that rougher surfaces of the heat flux density higher than smooth.

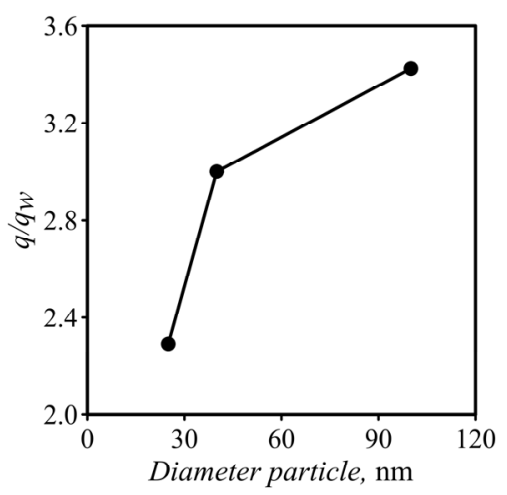

Figure 2. The dependence of heat flux density on the nanoparticles diameters (a)

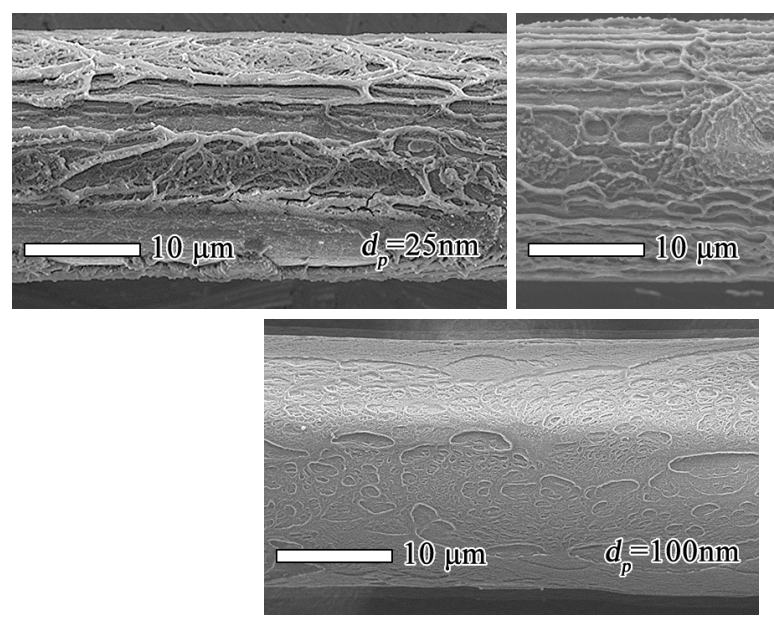

Figure 3. SEM images of nichrome wire surface after boiling for $0.05 \% \mathrm{SiO}_{2}$ concentration.

\section{Conclusions}

Boiling characteristics and CHF enhancement according to material, particle size, heater dimensions, and concentrations were investigated by pool boiling experiments of nanofluids. CHF is significantly enhanced in nanofluids (more than 3 times). CHF is enhanced even at very low concentrations. It is shown that there is a strong dependence CHF on the material and size of the nanoparticles. With increasing of the particle diameter the CHF increases. This is due to the dimensions of the roughness formed during the deposition of the particles. As the size of the heater flow is reduced. This is due to the influence of microflows around roughen the surface of the heater. It can assume that the surface particle interaction between the nanoparticles and the heating surface is the factor that causes an appreciable increase or decrease in $\mathrm{CHF}$, more than what can be accounted for by the fluid property variation. 
This work was partially financially supported by the Russian Science Foundation (Contract № 1419-00312).

\section{References}

1. S. Das, S. U. S. Choi, W. Yu, T. Pradeep, Nanofluids Science and Tecnology (Wiley Interscience, New Jersey, 2007).

2. X.Q. Wang, A. S. Mujumbar, International J. Thermal Sciences 46, 1 (2007).

3. V.Y. Rudyak, , A.V. Minakov, M.S. Smetanina, M.I. Pryazhnikov. Doklady Akademii Nauk. 467(3), 1-3 (2016).

4. V. Ya. Rudyak, Advances in Nanoparticles 2, 266 (2013).

5. V. I. Terekhov, S. V. Kalinina, V. V. Lemanov, Teplofiz. Aeromech. No. 2, 173 (2010).

6. D. V. Guzei, A. V. Minakov, V. Ya. Rudyak, A. A. Dekterev, Techn. Phys. Lett. 40, 203, (2014).

7. S. M. Kwark, R. Kumar, G. Moreno, J. Yoo, S. M. You, Int. J. Heat Mass Transfer 53 (5-6), 972 (2009).

8. S. K. Das, G. Narayan, and Baby A. K. Prakash, J. Nanopart. Res. 10 (7), 1099 (2008).

9. J. S. Coursey and J. Kim, Int. J. Heat Fluid Flow, 29 (6), 1577 (2008).

10. M. H. Shi, M. Q. Shuai, Z. Q. Chen, Q. Li, Y. Xuan, J. Enhanced Heat Transfer 14 (3), 223 (2007).

11. B. S. Fokin, M. Ya. Belen'kii, V. I. Al'myashev, V. B. Khabenskii, O. V. Al'myasheva, V. V. Gusarov, Pis'ma Zh. Tekh. Fiz. 35 (10), 1 (2009).

12. E. V. Timofeeva, D. S. Smith, W. Yu, D. M. France, D. Singh, J. L. Routbo, Nanotecnology 21, 215703 (2010).

13. A.V. Minakov, A.S. Lobasov, D.V. Guzei, M.I. Pryazhnikov, V.Ya Rudyak. ATE. 88,140-148 (2015).

14. A.V. Minakov, A.S. Lobasov, V.Y. Rudyak, D.V. Guzei, M.I. Pryazhnikov. Tech. Phys. Let. 40

(7), 562-564 (2014)

15. M.I. Pryazhnikov, A.V. Minakov, V.Y. Rudyak. Tech. Phys. Let. 41 (9), 891-893 (2015) 